\title{
A case study: Applying quality improvement methods to reduce pre-operative length of stay in a resource-constrained setting in Rwanda
}

\author{
Ssebuufu Robinson ${ }^{1}$, Victor Pawelzik ${ }^{2}$, Abraham Megentta ${ }^{2}$, Oswald Benimana ${ }^{1}$, Damascene Mazimpaka ${ }^{1}$, Jules \\ Ndoli $^{1}$, Augustin Sendegeya ${ }^{1}$, Rex Wong ${ }^{* 2}$ \\ ${ }^{1}$ CHUB hospital, Butare, Rwanda \\ ${ }^{2}$ Global Health Leadership Institute, Yale University, United States
}

Received: September 15, 2015

Accepted: October 30, 2015

Online Published: November 6, 2015

DOI: $10.5430 /$ jha.v5n $1 \mathrm{p} 41$

URL: http://dx.doi.org/10.5430/jha.v5n1p41

\begin{abstract}
Objective: While several studies have focused on improving the quality of surgery, less attention has been paid to reducing pre-operative delays in care. We undertook a hospital quality improvement (QI) effort to reduce pre-operative delays in a teaching hospital in Rwanda. Without a coordinated admission schedule, many surgical patients arriving at the hospital for admissions were turned away because of unavailable beds. For those admitted for surgery, the pre-operative waits were long.

Methods: A pre- and post-intervention study was conducted to examine the impact of a QI effort on two metrics: 1) pre-operative length-of-stay (LOS) for elective surgical patients, and 2) the number of elective surgical patients who were turned away on the scheduled admission date. Intervention: A multi-disciplinary work group utilized a Strategic Problem Solving Approach and implemented a centralized patient wait list and new schedule process utilizing the existing resources available at the hospital.

Results: The percentage of elective surgical patients with a pre-operative LOS of more than two days was significantly lower in the post-intervention compared with the pre-intervention period ( $80 \%$ versus $26.8 \%, p$-value $<.001)$. The percentage of scheduled patients who were turned away due unavailable inpatient beds significantly decreased from $63.4 \%$ to $5.3 \%, p$-value $<.001$.

Conclusions: By following a methodical strategic problem solving approach, the pre-operative LOS was reduced, elective surgical patients turned away due to unavailable beds was decreased at very low financial cost.
\end{abstract}

Key Words: Resource-constrained setting, Pre-operative length of stay, Quality improvement, Strategic problem solving, Patient schedule

\section{INTRODUCTION}

The operational effectiveness of surgical care is a key component of hospital quality. In the US, operating room efficiency is increasingly used as a marker of the quality of surgical care. In 2001, the Institute of Medicine identified efficiency and timeliness as two of six areas for improvement for US hospitals. ${ }^{[1]}$ Surgical care efficiency is particularly important in low-income countries where more than 8 million surgeries are performed per year with very limited resources. ${ }^{[2]}$

Although several studies have focused on improving the quality of surgery, ${ }^{[3,4]}$ less attention has been paid to preoperative delays in care - a critical problem for patients, staff, and the hospital overall. Pre-operative delays can result in hospital overcrowding and inefficiency. ${ }^{[5-11]}$ Delays in

${ }^{*}$ Correspondence: Rex Wong; Email: rex.wong@ yale.edu; Address: Global Health Leadership Institute, Yale University, United States. 
care can increase staff stress levels, reduce patient satisfaction, create financial burdens to hospitals, ${ }^{[12-14]}$ and even result in unintended consequences to patients such as unhealthy fasting. ${ }^{[15]}$ Most previous studies have focused on interventions to reduce post-surgical delays by addressing weak recovery and discharge processes ${ }^{[16-18]}$ and the vast majority of published studies have been conducted in highincome countries. We could find no studies that examined the impact of system-based interventions to reduce pre-operative length of stay (LOS) in a low-income setting.

Accordingly, we undertook a hospital quality improvement (QI) effort to reduce pre-operative delays in a low-income setting. QI methodologies have been adopted in western healthcare settings since the mid $1980 \mathrm{~s}^{[19]}$ and have recently been shown to be effective in improving hospital quality in some low-and middle-income countries (LMICs). ${ }^{[19-24]}$ In Egypt, a block scheduling system for cardiac used a strategic problem solving approach to reduce patient wait time by $13 \%$ and overcrowding by $50 \% .{ }^{[21]}$ In Ecuador, changing work processes and modifying staff work schedules reduced total patient waiting time by $43 \%$, which allowed physicians $45 \%$ more contact time with patients. ${ }^{[23]}$ Similarly, in Rwanda, the application of QI methods in an accident and emergency department successfully eliminated patients boarding in the hallways and reduced foot traffic by $28 \%$ without significant financial investment from the hospital. ${ }^{[25]}$ However, the use of QI to reduce elective surgical patient LOS has not been well documented. We selected Rwanda as an ideal site for such a study as the country is currently implementing a national initiative to improve hospital management capacity as part of the Rwanda Human Resources for Health $(\mathrm{HRH})$ project, sponsored by USAID and directed by the Rwandan Ministry of Health. ${ }^{[26]}$ Using a pre- and post-intervention study design, we tested the hypothesis that changes to scheduling would reduce elective surgical patient LOS, with little additional cost to the hospital. Findings from this study may be useful as a blueprint for other resourcelimited hospitals to reduce surgical delays.

\section{Methodology}

\subsection{Setting}

The QI project took place at a teaching hospital in Rwanda, which also serves as a referral hospital that receives patients from district hospitals in the country. The hospital had 113 surgical beds, an average occupancy rate of $83 \%$, and annual admissions of over 2,000 surgical patients. ${ }^{[27,28]}$ The surgical department is divided into five patient care teams (or firms). All firms admitted their elective surgical patients on Sundays despite the fact that each firm was assigned a different day of the week during which to perform surgeries.
After deciding a patient needed elective surgery, a consultant would tell the patient to return on a specific Sunday. Since individual consultants scheduled patients without a coordinated effort, the consultant did not know how many other patients were scheduled for admission on that same day, and so the total number of patients expected on a given Sunday was unknown. This posed a problem for the inpatient wards, since they had no knowledge of incoming admissions. As a result, elective surgical patients would often arrive at the hospital on a Sunday, as instructed, only to be turned away because of unavailable beds. Once admitted, elective surgical patients waited for days until their firm's assigned theatre space became available. If the assigned theater day for the firm was closer to the end of the week, patients under that particular firm may have to wait almost a week before surgery, causing unnecessarily long preoperative LOS.

\subsection{Study design and sample}

We conducted a pre- and post-intervention study to examine the impact of a QI effort on two metrics: 1) pre-operative LOS for elective surgical patients, and 2) the number of elective surgical patients who were turned away on the scheduled admission date. Only elective surgical cases were included in the study; all trauma and emergency cases were excluded. To calculate the pre-operative LOS, we audited files of all inpatients that had an elective surgical procedure during March - December, 2013 (10 months) as pre-intervention period and May 2014 - June 2015 (14 months) as postintervention period. For the percentage of scheduled patients who were turned away, we compared admission records to each firm's consultant calendars. Since not all consultants routinely recorded their scheduled patients on the calendars, we used all data we could collect from available calendars. The pre-intervention period included 14 months between February 2013 and March 2014, and the post-intervention period included 10 months between September 2014 and June 2015.

\subsection{Intervention}

In October 2013 a multi-disciplinary work group was convened to address the preoperative delay problem. The members of the work group included the hospital medical director, the surgical department head, the nurse managers of the surgical ward, the nurse in charge of the operating theatre, the HRH general surgery faculty at the hospital, and the HRH health management mentors. The team utilized a Strategic Problem Solving Approach. ${ }^{[26]}$ This systematic methodology consists of eight steps: defining the problem, setting an objective, conducting a root cause analysis, generating alternative strategies, comparing strategies, selecting a strategy, implementing the strategy, and evaluating its impact on the 
problem - in this case, preoperative delays (see Table 1).

Table 1. The eight-step strategic problem solving process. source: delmar, cengage learning
1. Define the problem;
2. Set the overall objective;
3. Conduct a root cause analysis;
4. Generate alternative strategies to interventions;
5. Perform a comparative analysis of alternatives;
6. Select the best strategy and address its limitations;
7. Develop an implementation plan and implement;
8. Develop an evaluation plan and evaluate.

The team defined the problem as excessive preoperative LOS for elective surgical cases and set an objective to reduce by $30 \%$ the percentage of patients who stayed more than 2 days pre-operatively within three months after implementation. The team spent four months conducting a root cause analysis, generating solutions and implementing the selected strategy. Essential information including bed occupancy rate, admission volume, each firm's theatre days, and patient demographics, were analyzed in the root cause analysis. Based on the root causes identified, the team identified the best strategy for intervention. The intervention was discussed with department staff, including physicians, residents, nurses, and other supporting staff, and was revised multiple times based on feedback from several pilot tests, following the Plan-Do-Study-Act (PDSA) cycle. ${ }^{[29,30]}$ The PDSA cycle is an ongoing, scientific QI process, used for action-oriented learning. A working team sets an aim and develops measures to determine whether a change leads to an improvement, then tests a change in the real work setting. The PDSA cycle focuses on by planning it, trying it, observing the results, and acting on what is learned. ${ }^{[29,30]}$

The intervention included several changes. First, starting in Feb 2014, elective surgical patients could be admitted any day of the week, not just on Sunday. In fact, each firm admitted its elective surgery patients two days before its assigned theatre day. Second, in April 2014, a central waiting list was created in order to avoid overbooking and to facilitate communication between firms and inpatient wards. Initially, the wait list was a paper-based system, but this was later migrated to an electronic system. The central wait list contains basic patient information, contact phone numbers and an urgency scale to facilitate prioritization, which was developed and agreed upon by surgeons from all firms (some examples of common diagnoses under the urgency scale were listed in Table 2). Third, the responsibility of admission scheduling was transferred from individual surgeons to the surgical ward nurse manager. The nurse manager took ownership of the list and was responsible for contacting patients to co-

Published by Sciedu Press ordinate their admission. Based on the availability of beds, surgeons, theatre rooms and medical consumables, the nurse manager would determine how many patients to schedule for admission for a particular day. Fourth, the electronic wait list system was developed, tested, and implemented in August 2014. This allows the scheduler to have an easy and dynamic overview of all key scheduling information. The electronic system also generates descriptive statistical reports, including a summary of patient demographics, categorized by urgency and firm, for the department to review.

Table 2. Examples of diagnoses under each category of urgency scale

\begin{tabular}{ll}
\hline Urgency scale & Examples of diagnoses \\
\hline Very urgent & Osteosarcoma, gastric outlet obstruction \\
Urgent & Retrosternal goiter, colorectal cancer \\
Not urgent & Lipoma, hydrocele, uncomplicated hernia \\
\hline
\end{tabular}

\subsection{Measures}

The primary measure was the percentage of patients who have pre-operative LOS longer than two days. In addition, we analyzed the percentage of elective surgery patients who were turned away from admission due to unavailable beds. We compared both measures before and after the implementation of our intervention.

\subsection{Data analysis}

We compared the percentage of elective surgical patients who had a pre-operative LOS greater than two days and the percentage of elective surgical patients who were turned away pre- and post-intervention due to bed unavailability. A chi square test was used for both comparisons, and the analyses were repeated with gender stratified. We also presented the average pre-operative LOS and the standard deviation as reference. All analyses were performed using SPSS version 17.0 (SPSS, Inc., Chicago) with the confidence level set at $p=.05$ to determine statistical significance.

\section{Results}

For pre-operative LOS, a sample of 199 and 224 were collected in the pre- and post-intervention period respectively. This represented approximately $38 \%$ and $30 \%$ of all elective cases performed annually in the hospital. There were $124(62.3 \%)$ and $151(68.6 \%)$ males and $75(37.7 \%)$ and 66 $(30.4 \%)$ females in the pre- and post-intervention periods. The gender mix did not differ significantly $(p=.117)$ between the pre- and post-intervention periods. We could not compare the patient age or surgery type due to incomplete documentation. We found that the percentage of elective surgical patients with a pre-operative LOS of more than two days was significantly lower in the post-intervention com- 
pared with the pre-intervention period ( $80 \%$ versus $26.8 \%$, centage of elective surgical patients who had a pre-operative $p$-value <.001) (see Table 3). Figure 1 shows the monthly per- LOS greater than two days.

Table 3. Comparison of pre-intervention and post-intervention LOS and percentage of patients being turned away on scheduled admission date

\begin{tabular}{|c|c|c|c|c|c|}
\hline & & Pre & Post & Change & $p$ \\
\hline \multicolumn{2}{|l|}{ Period } & Mar - Dec, 2013 & May $2014-$ Jun 2015 & & \\
\hline \multicolumn{2}{|l|}{$\mathrm{N}$} & 199 & 224 & & \\
\hline \multirow{2}{*}{ Gender } & $\mathrm{M}$ & $124(62.3 \%)$ & $151(69.6 \%)$ & & \multirow{2}{*}{.117} \\
\hline & $\mathrm{F}$ & $75(37.7 \%)$ & $66(30.4 \%)$ & & \\
\hline \multirow{2}{*}{ Pre-operative } & LOS $>2$ days & $156(80 \%)$ & $60(26.8 \%)$ & \multirow{2}{*}{$-53.2 \%$} & \multirow{2}{*}{$<.001^{* *}$} \\
\hline & LOS $\leq 2$ days & $39(20 \%)$ & $164(73.2 \%)$ & & \\
\hline \multicolumn{2}{|c|}{ Average pre-op LOS Day $(S D)$} & $10.34(+/-9.44)$ & $3.38(+/-6.02)$ & - & - \\
\hline \multicolumn{2}{|l|}{ Period } & Feb 2013 - Mar 2014 & Sep 2014 - Jun 2015 & & \\
\hline \multicolumn{2}{|l|}{$\mathrm{N}$} & 454 & 225 & & \\
\hline \multicolumn{2}{|c|}{ Scheduled patients being turned away } & $228(63.4 \%)$ & $12(5.3 \%)$ & \multirow{2}{*}{$89.4 \%$} & \multirow{2}{*}{$<.001^{* *}$} \\
\hline \multicolumn{2}{|c|}{ Patients admitted as scheduled } & $166(36.6 \%)$ & $213(94.7 \%)$ & & \\
\hline
\end{tabular}

${ }^{* *}$ Statistical significant at $p=.05$

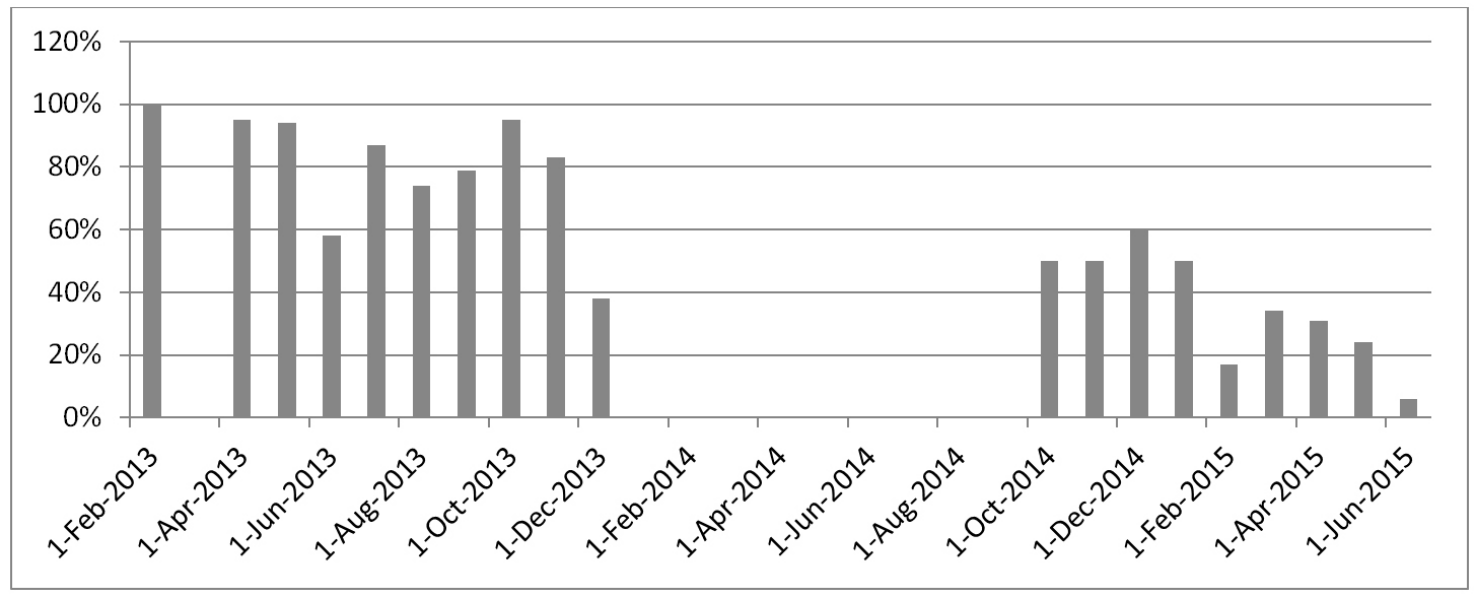

Figure 1. Percentage of patients with more than 2 days pre-operation LOS by month

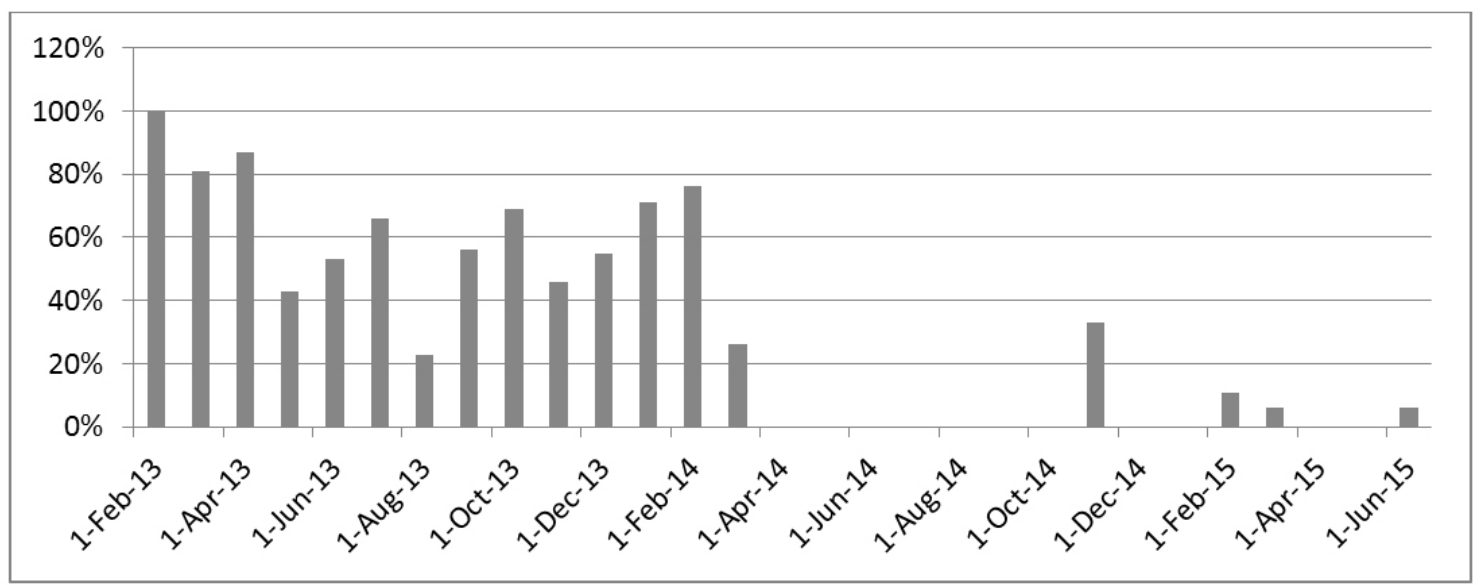

Figure 2. Percentage of patients being turned away due to no bed available by month 
For the percentage of scheduled patients who were turned away due unavailable inpatient beds, a sample of 454 and 225 were collected in the pre- and post-intervention periods respectively. We found that the percentage significantly decreased from $63.4 \%$ to $5.3 \%, p$-value $<.001$ (see Table 3 ). Figure 2 shows the monthly percentage of elective surgical patients who were turned away due to unavailable beds.

\section{Discussion}

Utilizing the strategic problem solving approach, ${ }^{[24]}$ the team successfully reduced elective surgery patients' pre-operative LOS and increased bed availability to elective surgery patients. Strategic problem solving's structure approach guided the team through systematic steps, starting with problem definition through monitoring and evaluation. Defining the problem statement helped focus the team on the key issue to be addressed. Conducting a root cause analysis revealed a general lack of data with which to assess the magnitude of the problem. There was no record of the number of elective surgery patient being turned away due to unavailable beds on admission date. As a result, the team decided to compare admission registers against each firm's individual calendar. However, individual firms and surgeons recorded their patients' appointments differently, requiring the team to compare the records line-by-line in order to generate useable data. This data-driven, evidence-based root cause analysis, though labor intensive, was crucial to understanding the problem and formulating the intervention.

A team approach was essential to the success of the project. The multi-disciplinary team met on regular basis to analyze the data. The goal was to understand the problem and create solutions around which the entire team could agree; allowing a wide spectrum of perspectives and facilitating communication to the entire department.

An effective, controlled admissions process could not be possible without communication and coordination among staff in the outpatient clinic, emergency room, operating theatre, and the surgical inpatient wards. Our central wait list not only created a common solution, it also provided a platform for intra- and inter-departmental communications.

Leadership support was essential. A member of the hospital senior management team and the head of the surgical department were recruited to the working group. Their participation demonstrated their support of the project. The department agreed to assign staff to manage the wait list and the hospital allocated budget and phones to allow the department to contact patients for scheduling. At the initial phase of the project, some staff were reluctant to participate in the changes. Applying the change management principles

Published by Sciedu Press by Kotter, ${ }^{[31]}$ we spent time with the staff to discuss and explain the new work process. We soon realized the staff perceived the new system was additional workload and also felt uneasy about using computer. The misunderstanding and fear drove the staff to stay status quo, despite they were fully aware of the problems of the old system. The department head clarified the misunderstanding rapidly; reminded the staff consistently and persistently of the importance of the project and spent time providing one-on-one coaching and guidance until the staff felt comfortable to change.

The team also regularly collected and provided feedback. Evaluation results showed initial improvement and were presented to department and hospital staff. This positive feedback encouraged staff to continue to participate, to improve the process and to take ownership. The hospital has a shortage of staff, and the surgical backlog was approximately three months long. With such high patient volume, many staff members were skeptical about the value of QI projects. Providing them information on the initial success of the intervention became crucial to help them see the benefits of the program.

The intervention was relatively simple and low cost. We created a standard wait list form for all surgeons to fill out. The form includes standard patient information and contact details and requires minimal time for the surgeons to complete. All completed forms are compiled daily into the central wait list. The surgeons are no longer required to schedule patients, a nurse manages the wait list and calls patients to schedule an appointment according to bed availability and the firms' theatre dates. Such clear division of labor enhanced the coordination of the admission process. When patients were scheduled to be admitted only two days before surgery, unnecessary pre-operative days at the hospital are minimized. The electronic wait list was created using MS Access software. The electronic wait list database was accessible at different areas of the department via the already existing hospital intranet. Statistical reports, which were previously difficulty to acquire, are now available instantly via the computer system. Apart from the human resources and time spent in the assessment and analysis, the project only incurred an additional cost of approximate 7 USD per month for phone calls.

The initial successes of this project generated a lot of new research and QI interests. The data captured by the database are routinely incorporated into making evidence-based decisions in the department. More outcome impact studies are expected to be conducted in the ensuing months.

The QI project was not without challenges. First, there was a general lack of proper documentation with which to measure 
the size of the problem. Multiple sources were explored yet almost none offered complete and consistent data. As a result, the sample sizes and pre- and post-intervention assessment periods for the two outcome measures were different. The exact number of elective surgery patients was impossible to acquire as surgeons did not record this information consistently or completely. As a result, the percentage of elective surgery patients turned away due to unavailable beds was almost certainly an underestimation. Similarly, the firm responsible for the patient was not consistently recorded in the medical files, making it impossible to assess individual firm performance. In addition to the poor documentation, many medical records could not be found due to mis-archiving, which created significant challenges in our assessment. Second, during this project, the department was renovating the surgical theatres and wards, so some units were moved to different locations. Implementing a new system while the department was undergoing renovations imposed significant coordination challenges. The team had to spend extra time and effort monitoring implementation progress. Third, hospital intranet service was affected by inconsistent electricity supply. The information technology department does not have the capacity to install uninterrupted power supply to

\section{REFERENCES}

[1] Institute of Medicine. Crossing the Quality Chasm: A New Health System for the $21^{\text {st }}$ Century. Washington, DC: National Academy Press; 2001. http://dx. doi .org/10.1186/1471-2261-3-9

[2] Weiser T, Regenbogen S, Thompson K, et al. An estimation of the global volume of surgery: a modelling strategy based on available data. Lancet. 2008; 372(9633): 139-44. http://dx. doi .org/10 1016/S0140-6736(08)60878-8

[3] Haynes A, Weiser T, Berry W, et al. A Surgical Safety Checklist to Reduce Morbidity and Mortality in a Global Population. N Engl J Med. 2009; 360: 491-499. PMid: 19144931. http: //dx.doi.org/10.1056/NEJMsa0810119

[4] Bradley EH, Nallamothu BK, Herrin J, et al. National Efforts to Improve Door-to-Balloon Time: Results from the Door-to-Balloon Alliance. Journal of the American College of Cardiology. 2009; 54: 2423-9. PMid: 20082933. http://dx.doi.org/10.1016/j.jac c. 2009.11 .003

[5] Fatovich DM, Nagree Y, Sprivulis P. Access block causes emergency department overcrowding and ambulance diversion in Perth, Western Australia. Emerg Med J. 2005; 22: 351-4. PMid: 15843704. http://dx.doi.org/10.1136/emj.2004.018002

[6] Canadian Institute for Health Information. Understanding emergency department wait times: access to inpatient beds and patient flow. Ottawa (ON): The Institute; 2007 (accessed 31 Oct 2014).

[7] Schull MJ, Slaughter PM, Redelmeier DA. Urban emergency department overcrowding: defining the problem and eliminating misconceptions. CJEM. 2002; 4: 76-83. PMid: 17612424. the entire hospital. Fourth, a shortage of staff made ongoing assessment of the intervention's impact more challenging.

Despite the success of the intervention, this project was not without limitations. The study did not measure any intervention-related changes to staff or patient satisfaction. The intervention was only conducted in one hospital in one country, and so generalizability cannot be determined at this point. Evaluation was conducted after one year postimplementation, and so additional follow up is needed to assess project sustainability.

\section{Conclusion}

Applying a strategic problem solving approach aimed to reduce surgical ward overcrowding resulted in decreased elective surgical patient pre-operative LOS in a resourcechallenged setting By following a methodical problem solving approach and changing work process and flow, preoperative LOS was reduced, elective surgical patients turned away due to unavailable beds was decreased, and overall patient admission flow was enhanced. Our results showed that a strategic problem solving process can help improve operational efficiency at hospitals in resource-limited settings at very low financial cost.

[8] Asplin BR, Magid DJ. If you want to fix crowding, start by fixing your hospital. Ann Emerg Med. 2007; 49: 273-4. PMid: 17317503. http: //dx.doi.org/10.1016/j.annemergmed.2007.01.012

[9] Forster AJ. An agenda for reducing emergency department crowding. Ann Emerg Med. 2005; 45: 479-81. PMid: 15855940. http: //dx.doi.org/10.1016/j.annemergmed.2004.11.027

[10] Olshaker JS, Rathlev NK. Emergency department overcrowding and ambulance diversion: the impact and potential solutions of extended boarding of admitted patients in the emergency department. J Emerg Med. 2006; 30: 351-6. PMid: 16677993. http: //dx.doi.org/10.1016/j.jemermed.2005.05.023

[11] Canadian Association of Emergency Physicians. Joint Position Statement on emergency department overcrowding. CJEM. 2001; 3: 82-8 PMid: 17610795 .

[12] Cardoen B, Demeulemeester E, Beliën J. Operating room planning and scheduling: A literature review. European Journal of Operational Research. 2010; 201(3): 921-932. http://dx.doi.org/10.1016 /j.ejor.2009.04.011

[13] VanBerkel PT, Blake JT. A comprehensive simulation for wait time reduction and capacity planning applied in general surgery. Health Care Manage Sci. 2007; 10: 373-385. http://dx.doi.org/10. 1007/s10729-007-9035-6

[14] Proudlove NC, Gordon K, Boaden R. Can good bed management solve the overcrowding in accident and emergency departments? Emerg Med J. 2003; 20(2): 149-155. PMid: 12642528. http: //dx.doi.org/10.1136/emj.20.2.149

[15] Gebremedhn EG, Nagaratnam VB. Audit on preoperative fasting of elective surgical patients in an African academic medical cen- 
ter. World J Surg. 2014; 38(9): 2200-4. PMid: 24748347. http: //dx.doi.org/10.1007/s00268-014-2582-3

[16] DeCoster C, Roos NP, Carriere KC, et al. Inappropriate hospital use by patients receiving care for medical conditions: targeting utilization review. CMAJ. 1997; 157: 889-96. PMid: 9327796.

[17] McClaran J, Tover Berglas R, Glass KC. Chronic status patients in a university hospital: bed day utilization and length of stay. CMAJ. 1991; 145: 125-65.

[18] Chen A, Sabharwal S, Akhtar K, et al. Time driven activity based costing of total knee replacement surgery at a London teaching hospital. Knee. 2015 Jul 30; pii: S0968-0160(15)00160-X.

[19] Berwick DM, Godfrey AB, Roessner J. Curing Health Care: New Strategies for quality Improvement. San Francisco: Jossey-Bass; 2002.

[20] Bradley E, Hartwig KA, Rowe LA, et al. Hospital quality improvement In EthiopIa: A partnership mentoring model. Int J Qual Health Care. 2008; 20(6): 392-399. PMid: 18784268. http://dx.doi.o $\mathrm{rg} / 10.1093 /$ intqhe/mzn042

[21] Wong R, Hathi S, Linnander EL, et al. Building Hospital Management Capacity to Improve Patient Flow for Cardiac Catheterization at a Cardiovascular Hospital in Egypt. Jt Comm J Qual Patient Saf. 2012 Apr; 38(4): 147-53. PMid: 22533126.

[22] Proudlove NC, Gordon K, Boaden R. Can good bed management solve the overcrowding in accident and emergency departments? Emergency Medicine Journal. 2003; 20(2): 149-55. PMid: 12642528. http://dx.doi.org/10.1136/emj.20.2.149
[23] Hermida J, Laspina C, Idrovo F. Reducing Patient Waiting Times through Quality Assurance Methods in La Troncal, Ecuador. Bulleti of PAHO. 1996; 30(2): 118-124.

[24] Banaszak-Holl J, Nembhard I, Taylor L, et al. Cengage Learning, Chapter 2. Leadership and Management: A framework for action.

[25] Byiringiro JC, Wong R, Davis C, et al. Applying quality improvement principles to improve accident and emergency department overcrowding and flow in Rwanda: a case study. Journal of Hospital Administration. 2015; 4(5): 47- 51. http://dx.doi.org/10.54 30/jha.v4n5p47

[26] Binagwaho A, Kyamanywa P, Farmer PE, et al. The human resources for health program in Rwanda-new partnership. N Engl J Med. 2013; 369(21): 2054-9. http://dx.doi.org/10.1056/NEJMsr13021 76

[27] Central Hospital University of Butare Narrative Report 2012-2013.

[28] Central Hospital University of Butare, Surgical Department Statistic Report 2014-2015.

[29] Langley GL, Nolan KM, Nolan TW, et al. The Improvement Guide: A Practical Approach to Enhancing Organizational Performance ( $2^{\text {nd }}$ Edition). Jossey Bass, San Francisco; 2009.

[30] Available from: http://www.ihi.org/IHI/Topics/Improve ment/ImprovementMethods/HowToImprove/

[31] Kotter J, Schlesinger L. Choosing strategies for change. Harvard Business Review. 2008. 